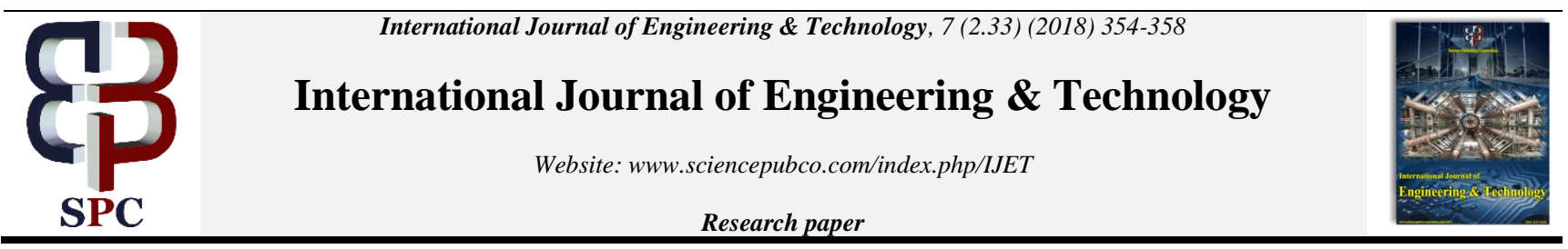

\title{
Analysis of correlation of climate factors affecting solar power generation
}

\author{
Bok-Jong Yoo ${ }^{1}$, Chan-Bae Park ${ }^{2}$, Ju-Lee ${ }^{1}$ \\ ${ }^{1}$ Dept. of Electrical Engineering, Hanyang University, 222, Wangsimni-ro, Seongdong-gu, Seoul, 04763, Korea \\ ${ }^{2}$ Dept. of Railroad Operation System Engineering, Korea National University of Transportation,157, Cheoldobangmulgwan-ro, Ui- \\ wang-si, Gyeonggi-do, 16106, Korea \\ *Corresponding author E-mail: cbpark@ut.ac.kr
}

\begin{abstract}
Background/Objectives: In designing the solar power generation, feasibility review and power generation volume prediction during guarantee phase after the completion are very important.

Methods/Statistical analysis: The study compares the actual power generation volume obtained from solar power generation monitoring system and estimated volume calculated using overseas meteorological data from Meteonorm 7.1 and NASA-SSE and Korean data from the Korea Meteorological Administration, in order to understand their accuracy. The calculation using KMA data, with the highest prediction value, was used to analyze the correlation among solar radiation, temperature, and solar power generation volume.

Findings: Previous solar power generation volume prediction was conducted only with solar radiation value, which caused errors between the actual and predicted solar power generation volume. The study found that the power generation volume and solar radiation have a high positive correlation coefficient of 0.8131 for Songam Power Plant. For correlation between power generation volume and temperature, the coefficient for Songam was 0.2843 and 0.4616 for Jipyeong Power Plant, showing lower influence than that of solar radiation. In sum, solar radiation influences the solar power generation volume more than temperature, but the current study indicates that both solar radiation and temperature must be considered for an accurate prediction of solar power generation volume.

Improvements/Applications: Research to develop solar power generation volume prediction algorithm that takes into account both solar radiation and temperature must be conducted to expand the application of solar power generation system with more accurate estimation of power generation volume.
\end{abstract}

Keywords: Photovoltaic Power Generation; Low Carbon Energy; Photovoltaics; PV System; Photovoltaic Power Generation Prediction

\section{Introduction}

Korea's current interest in photovoltaic power generation is higher than ever, due to the signing of the Paris Agreement (2015.12), which is the main flow of global climate change response, and the Korean government's policy shift to renewable energy. Prediction of solar power generation plays an important role in reviewing the feasibility of the project at the design stage of solar power plant and at the stage of assuring the generation capacity after constructing the solar power plant. In order to compare actual power generation with predicted power generation, two currently operated solar power plants capable of obtaining actual power generation and meteorological data were selected as the target sites. The actual power generation and the predicted power generation using Meteonorm7.1, NASA-SSE overseas meteorological data and Korean meteorological office (KMA) meteorological data were compared [1]. The climate factors affecting power generation were analyzed through the actual power generation and the power generation using KMA weather data showing the most accurate predicted power generation and the correlation analysis technique for solar radiation, temperature and each of the climate factors.

\section{Equivalent circuit of solar cell}

Solar power generation is heavily dependent on climate factors such as solar radiation and temperature. Solar cell can be regarded as a very small virtual power generator or photodiode. The equivalent circuit of the solar cell is represented by a current source with parallel diode, series resistance $\left(R_{\mathrm{s}}\right)$ and shunt resistance $\left(\mathrm{R}_{\mathrm{sh}}\right)$ as shown in Fig.1.

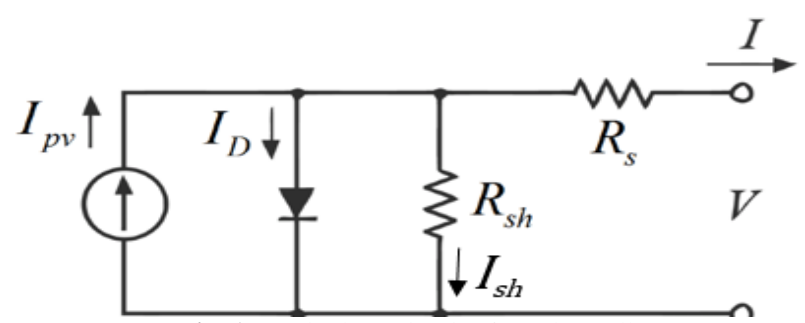

Fig. 1: Equivalent Circuit of a Solar Cell. 


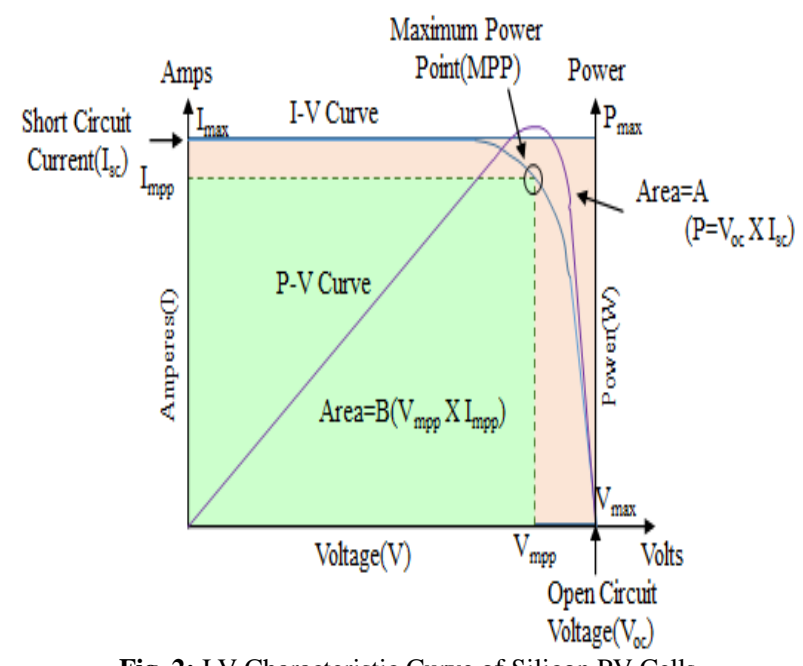

Fig. 2: I V Characteristic Curve of Silicon PV Cells.

In the equivalent circuit of solar cell, the output current I is given by equation (1) from Kirchhoff's law.

$$
I=I_{p v}-I_{D}-I_{s h}
$$

If this is converted again, it is expressed by the following equation (2).

$$
I=I_{p v}-I_{0}\left[\exp \left(\frac{V+I R_{s}}{\alpha V_{T}}\right)-1\right]-\frac{V+I R}{R_{s h}}
$$

Where, $\mathrm{I}_{\mathrm{pv}}$ is the photocurrent transmitted by the constant current source, $I_{D}$ is the current flowing through the diode, $I_{0}$ is a reverse saturation current corresponding to the diode, $R_{S}$ is the series resistance considering losses of interconnections and junction boxes, and $R_{\text {sh }}$ is the shunt resistor that takes into account the current leakage passing through the high-conductivity shunt via p-n junction. $\alpha$ is the ideal coefficient considering the diode deflection from Shockley diffusion theory. $\mathrm{V}_{\mathrm{T}}$ is the thermal voltage of diode, which is related to the charge of electrons q, Boltzmann constant $\mathrm{k}$, the number of cells $\mathrm{n}$, and temperature $\mathrm{T}$ and is given by equation (3) [2].

$$
V_{T}=n \frac{k T}{q}
$$

Fig. 2 shows the I-V characteristic curve, and the decrease in solar radiation dose affect most of the modules currents, and the module output decreases. Temperature has little effect on the current change of solar module, and the module current only rises slightly when the temperature rises [3]. The open-circuit voltage $\left(\mathrm{V}_{\mathrm{oc}}\right)$ decreases proportionally and the output decreases when the temperature rises above the reference temperature of $25^{\circ} \mathrm{C}$, which is the standard test conditions [4].

\section{Solar power generation prediction algo- rithm}

A general solar power generation prediction algorithm is shown in Fig.3 [5].

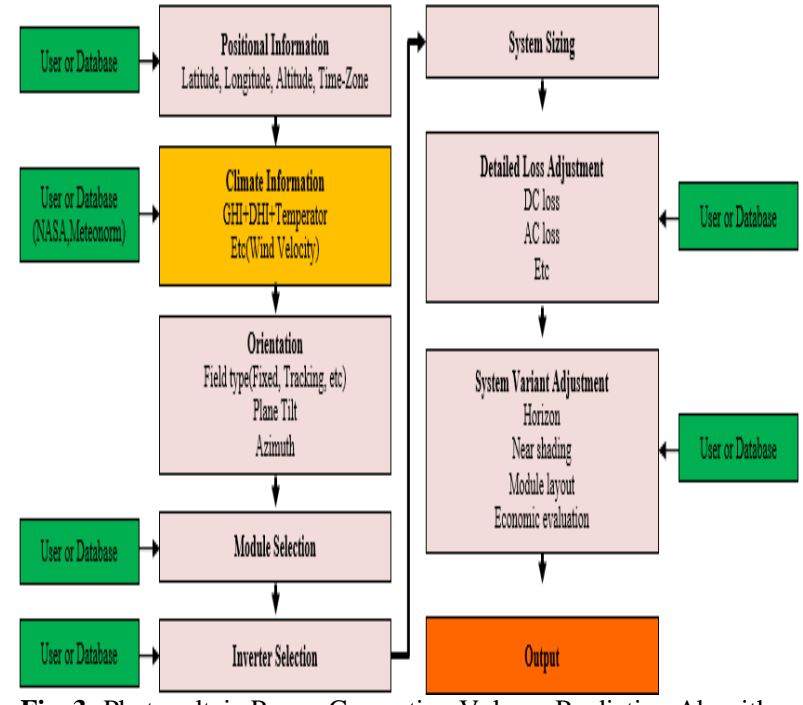

Fig. 3:.Photovoltaic Power Generation Volume Prediction Algorithm.

After inputting the location information of the prediction site of power generation, Meteonorm or NASA-SSE overseas meteorological data are selected or the meteorological data of the site or the meteorological data of the domestic meteorological office (KMA) as in this study are inputted. Select the installation angle of Photovoltaic (PV) array, adjustment of seasonal inclination angle and the installation type of PV array such as fixed type, variable type, and tracking type. After selecting the solar module and inverter, system sizing is performed to design the optimum number of serial and parallel lines according to the maximum power point of the selected module and inverter. This is an algorithm that estimates the output power after the adjustment stage of system losses such as the resistance loss of cable or no load loss of transformer and system parameters of solar power plant such as the shading effect.

The annual power generation formula of solar power generation can be simplified as shown in Equation (4) [3], [6-8]. Here, the performance ratio PR (performance ratio) of the solar power generation system is determined by the ratio of the DC input, which is the installation capacity in the standard test conditions (STC) of the solar module and the AC output considering the total loss of solar power system and it is an index for evaluating the performance degradation and loss factors of the system. Generally, it is judged that the PR is good when it is more than $80 \%$, and when it is less than $70 \%$, there are defects of parts, shading, and construction problems related to the solar power generation system [9].

$P_{\text {year }}=I_{t} \times M_{\text {eff }} \times A \times P R$

Where, $P_{y e a r}$ is the annual solar power generation $[\mathrm{kWh}], \mathrm{It}_{\mathrm{t}}$ is the total annual solar radiation on the plane of array $\left[\mathrm{kWh} / \mathrm{m}^{2}\right], \mathrm{M}_{\mathrm{eff}}$ is the solar module efficiency [\%], A is the PV array area $\left[\mathrm{m}^{2}\right]$, and PR (Performance Ratio) represents the system performance ratio [\%], respectively.

Temperature is considered simply as one of the loss factors of the system performance ratio (PR). In PVsyst, the solar loss in accordance with temperature is applied based on Faiman's module temperature calculation formula, and it is as shown in equation (5) [10].

$$
T_{c}=T_{a}+\frac{\alpha E_{e}\left(1-\eta_{m}\right)}{U_{0}+U_{1} W S}
$$

Where, $\mathrm{T}_{\mathrm{c}}$ is the cell temperature of module $\left[{ }^{\circ} \mathrm{C}\right], \mathrm{T}_{\mathrm{a}}$ is the ambient temperature of module $\left[{ }^{\circ} \mathrm{C}\right]$, and $\alpha$ is the module absorption coefficient, generally $0.9 . \eta_{\mathrm{m}}$ is the efficiency of the module, generally $0.08 \sim 0.2$, but 0.1 is basically applied for PVsyst and WS is the wind speed $[\mathrm{m} / \mathrm{s}] . \mathrm{U}_{0}$ is the heat transfer coefficient $\left[\mathrm{W} / \mathrm{m}^{2} \mathrm{~K}\right]$, 
generally $23.5 \sim 26.5$. $\mathrm{U}_{1}$ is a convective heat transfer coefficient $\left[\mathrm{W} / \mathrm{m}^{2} \mathrm{~K} / \mathrm{m} / \mathrm{s}\right.$ ], generally $6.25 \sim 7.68$.

For the default values applied to the actual PVsyst, the module absorption coefficient $\alpha$ is 0.9 , the module efficiency $\eta_{\mathrm{m}}$ is 0.1 , and $\mathrm{U}_{1}=0$ is applied assuming that it does not depend on the wind speed. For the default values of convective heat transfer coefficient $\mathrm{U}_{0}, \mathrm{U}_{0}=29$ is applied for an open stand-alone PV array and $\mathrm{U}_{0}=15$ for a fully closed PV array [5], [11].

\section{Comparison between actual generation and estimated generation by meteorological data}

In order to compare the actual power generation and predicted power generation based on the Meteonorm7.1, NASA-SSE overseas weather data and KMA weather forecast data, two solar power plants in Korea from which actual power generation and meteorological data can be acquired from the currently operated solar power monitoring system installed in the power plant were selected. The details of the sites are as shown in Table 1. The Jipyeong Solar Power Plant is a 3MW floating type solar power plant that has been in commercial operation for two years since July 2015. Songam Solar Power Plant is a $2 \mathrm{MW}$ ground-based solar power plant that has been in commercial operation for three years since February 2014.

Table 1: PV Plant Site Information

\begin{tabular}{lll}
\hline Site Information & Jipyeong PV Plant & Songam PV Plant \\
\hline Latitude / Longitude & $36^{\circ} 32^{\prime} 59.67^{\prime \prime} \mathrm{N}$, & $37^{\circ} 51^{\prime} 31.89^{\prime \prime} \mathrm{N}$, \\
Altitude[m] & $128^{\circ} 6^{\prime} 50.10^{\prime \prime} \mathrm{E}$ & $127^{\circ} 40^{\prime} 47.29 " \mathrm{E}$ \\
Photovoltaic Capacity & $97.61 \mathrm{~m}$ & $81 \mathrm{~m}$ \\
[MW] & DC $3.0876 \mathrm{MW}$ & DC $2.050 \mathrm{MW}$ \\
Module[Wp] & $310 \mathrm{Wp}(9,960 \mathrm{pcs})$ & $250 \mathrm{Wp}(8,200 \mathrm{pcs})$ \\
Inverter[Kw] & $990 \mathrm{~kW}(3 \mathrm{pcs})$ & $500 \mathrm{~kW}(4 \mathrm{pcs})$ \\
Array Tilt $\left[{ }^{\circ}\right]$ & Fixed $12^{\circ}$ & Variable $15 \sim 45^{\circ}$ \\
\hline
\end{tabular}

The actual power generation obtained from the solar monitoring system installed in solar power plant and the predicted results using the overseas weather data of Meteonorm7.1, NASA-SSE and the weather data of KMA are shown in Table 2. In both sites, the most accurate power generation prediction compared to the actual power generation is the one using the weather data of KMA.
Table 2: Comparison of Actual Power Generation Volume and Simulated Power Generation Volume

\begin{tabular}{llll}
\hline PV Plant & $\begin{array}{l}\text { Jipyeong PV } \\
\text { Plant }\end{array}$ & $\begin{array}{l}\text { Songam PV } \\
\text { Plant }\end{array}$ & \\
\hline Period & $15.07 \sim 17.04$ & $14.02 \sim 17.04$ & \\
Actual Power Generation & $6,881.6$ & $9,575.9$ & \\
Volume[MWh] & $6,512.3(-$ & $8,542.3(-$ & The number \\
Meteonorm7.1[MWh] & $5.37 \%)$ & $12.10 \%)$ & in ( ) marks \\
& $8,036.7$ & $10,920.0$ & an error rate \\
NASA-SSE[MWh] & $(16.79 \%)$ & $(12.31 \%)$ & \\
& $6,727.5(-$ & $8,700.3(-$ & \\
KMA[MWh] & $2.27 \%)$ & $10.06 \%)$ & \\
\hline
\end{tabular}

\section{Correlation analysis between predicted power generation and climate factors in Korean terrain}

The comparison of the solar radiation (GHI) and temperature of KMA which has the highest prediction accuracy and the actual solar radiation, temperature and power generation obtained from the solar monitoring system is shown in Table 3.

Table 3: Comparison of Measurement Value and Simulated Value

\begin{tabular}{|c|c|c|c|c|c|}
\hline $\begin{array}{l}\text { PV } \\
\text { Plant }\end{array}$ & $\begin{array}{l}\text { Period } \\
\text { [Month] }\end{array}$ & \multicolumn{2}{|c|}{ Measurement Value } & \multicolumn{2}{|l|}{ KMA } \\
\hline & & $\begin{array}{l}\text { GHI[KW } \\
\left.\mathrm{h} / \mathrm{m}^{2}\right]\end{array}$ & $\begin{array}{l}\text { Amb. } \\
\text { Temp[ } \\
\left.{ }^{\circ} \mathrm{C}\right]\end{array}$ & $\begin{array}{l}\text { GHI[KW } \\
\left.\mathrm{h} / \mathrm{m}^{2}\right]\end{array}$ & $\begin{array}{l}\text { Amb. } \\
\text { Temp[ } \\
\left.{ }^{\circ} \mathrm{C}\right]\end{array}$ \\
\hline $\begin{array}{l}\text { Ji- } \\
\text { pyeong }\end{array}$ & $\begin{array}{l}15.07 \sim 17.0 \\
4\end{array}$ & $2,186.36$ & 11.84 & $2,223.30$ & 11.12 \\
\hline Songam & $\begin{array}{l}14.02 \sim 17.0 \\
4\end{array}$ & $4,087.95$ & 21.76 & $4,164.90$ & 10.76 \\
\hline
\end{tabular}

When analyzing the correlation between the solar power generation, actual solar radiation and temperature and the solar radiation and temperature of KMA data, there is positive correlation between the power generation and solar radiation, and power generation and temperature as shown in Fig.4 and Fig.5. The correlation coefficients between the solar power generation, solar radiation (GHI) and temperature are as shown in Table 4.

(B) KMA (Jipyeong)

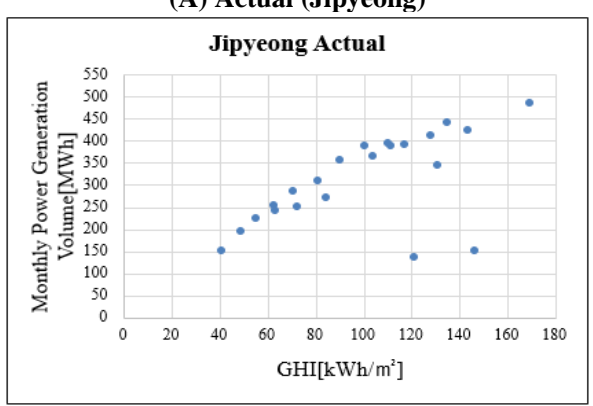

(C) Actual (Songam)

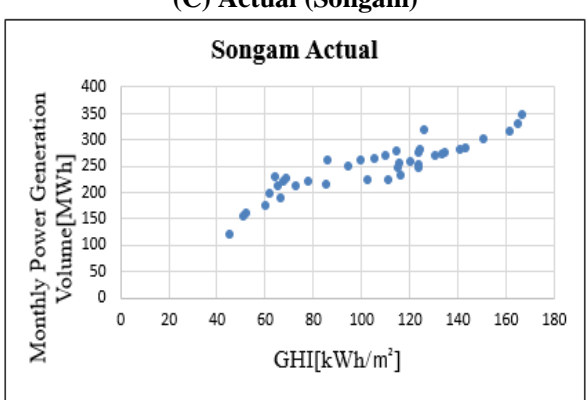

\section{Jipyeong KMA}

(D) KMA (Songam)

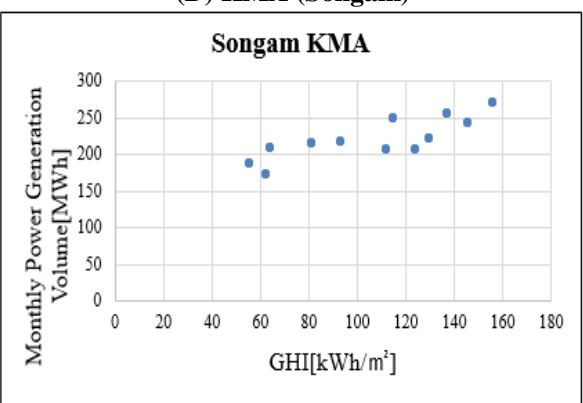

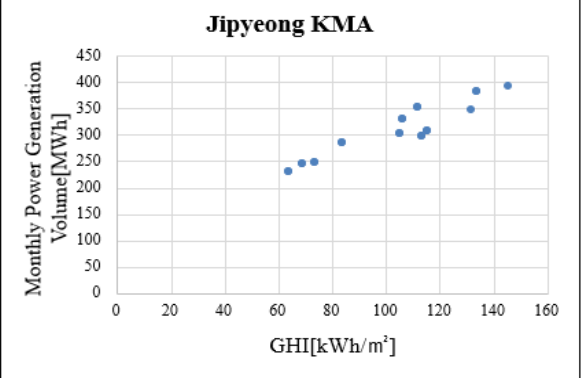

Fig. 4:.Analysis of Correlation between the Power Generation Volume and GHI. 


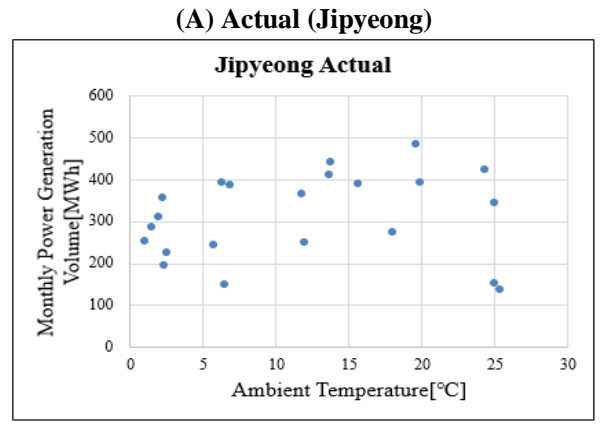

(C) Actual (Songam)

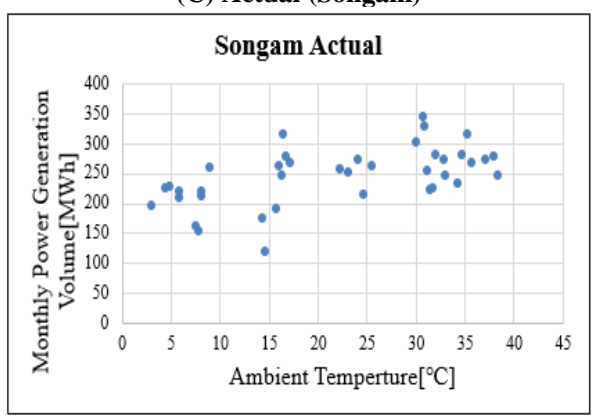

(B) KMA (Jipyeong)

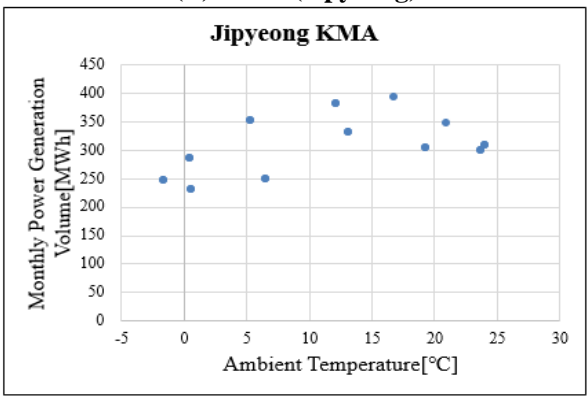

(D) KMA (Songam)

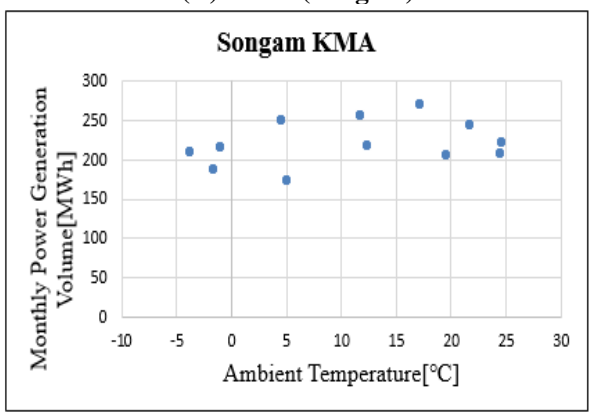

Fig. 5:.Analysis of Correlation between the Power Generation Volume and Ambient Temperature.

Table 4: Correlation Coefficient of the Power Generation Volume and GHI and Ambient Temperature

\begin{tabular}{lllll}
\hline Power Generation Volume [MWh] & Period [Month] & Measurement & & KMA \\
\hline & & GHI $\left[\mathrm{kWh} / \mathrm{m}^{2}\right]$ & Amb.Temp $\left[{ }^{\circ} \mathrm{C}\right]$ & $\mathrm{GHI}\left[\mathrm{kWh} / \mathrm{m}^{2}\right]$ \\
Jipyeong PV Plant & $15.07 \sim 17.04$ & 0.5883 & 0.1444 & 0.9378 \\
Songam PV Plant & $14.02 \sim 17.04$ & 0.9046 & 0.5570 & 0.4616 \\
\hline
\end{tabular}

In the case of Songam Solar Power Plant, where the correlation coefficient between power generation and solar radiation is low, the correlation coefficient is 0.8131 , which shows that there is a high correlation between power generation and solar radiation. Correlation coefficient between power generation and ambient temperature was analyzed to be 0.2843 in the case of Songam solar power plant and 0.4616 in the case of Jipyeong solar power plant. According to the results of analysis, solar radiation has the greatest influence on the solar power generation and temperature has less correlation than solar radiation, however, it can be seen that it is necessary to consider both the solar radiation and temperature to predict the generation amount accurately.

\section{Conclusion}

Prediction of solar power generation volume is significant in the design stage of the feasibility study of solar power plant construction project and in the stage of assuring the power generation volume after the power plant construction. Solar power generation volume prediction to this date has been conducted by considering only the solar radiation as the main climatic factor, which decreased the accuracy, and the temperature has been treated as merely a partial loss factor of the performance ratio of the solar power generation system. In this study, solar radiation and temperature were considered as factors correlated to the photovoltaic power generation volume, while using the correlation analysis technique; the results indicated that both meteorological factors are positively correlated with solar power generation volume. The correlation coefficient of solar radiation, the main factor influencing the solar power generation volume, was 0.8131 for Songam Power Plant (which has a lower correlation among studied sites), while the correlation coefficient of temperature was 0.2843 , a lower value that solar radiation. However, the analysis indicated that higher power generation volume prediction power can be obtained only by considering both solar radiation and temperature. In the future, it is necessary to expand the application of solar power generation system by predicting accurate generation amount by developing solar power generation prediction algorithm that considers accurate temperature factor together with solar radiation.

\section{Acknowledgment}

This work was supported by the National Research Foundation of Korea(NRF) grant funded by the Korean government(MSIP: Ministry of Science, ICT and Future Planning) in 2016. (No. 2016R1D1A1B03932224)

\section{References}

[1] Korea Meteorological Administration. (2008). an analysis of meteorological resources for optimal utilization of solar energy. Retrieved from http://www.weather.go.kr/download_01/climate_energy.pdf.

[2] Cubas, J., Pindado, S., \& De Manuel, C. (2014). Explicit expressions for solar panel equivalent circuit parameters based on analytical formulation and the lambert W-function. Energies, 7(7), 40984115.doi:10.3390/en7074098.

[3] LEE, H. H. (2009). Photovoltaic Power Generation for Low Carbon Green Growth, Seoul.Kidari Publishing Corp. Retrieved from: http://www.kidari.co.kr/front/php/product.php?product_no=12\&ma in_cate_no $=12 \&$ display_group $=1$.

[4] Tobnaghi, D. M., Madatov, R., \&Naderi, D. (2013). The Effect of Temperature on Electrical Parameters of Solar Cells.International Journal of Advanced Research in Electrical Electronics and Instrumentation Engineering, 2(12), 6404-6407.

[5] PVsyst. (2014). PVSYST USER'S MANUAL.Retrieved from: http://www.pvsyst.com/images/pdf/PVsyst_Tutorials.pdf.

[6] Yoo, B.J., Park, C.B. \&Lee, J. (2016) A study on design of $1.5 \mathrm{MW}$ photovoltaics power generation system using Gwangmyeong railway station building, Journal of the Korean Society for Railway,19(5), 592-599.doi:10.7782/JKSR.2016.19.5.592.

[7] Yoo, B.J. \&Lee, J. (2017) A study on photovoltaic power generation amount forecast at design stage for extended application in the field of railways, Journal of the Korean Society for Railway, 20(2), 182-189. doi:10.7782/JKSR.2017.20.2.182. 
[8] Yoo, B. J., Park, C.B. \& Lee, J.(2017) Comparative study to predict power generation using meteorological information for expansion of Photovoltaic power generation system for railway infrastructure, Journal of the Korean Society for Railway, 20(4), 474481.doi:10.7782/JKSR.2017.20.4.474.

[9] Kim B.J., Park, J.W., Yun, J.H, \&Shin.W.C. (2015) the development of performance evaluation program of building integrated photovoltaic system, Korea Institute of Ecological Architecture En-
vironment
Journal,
15
(4),
$85-$

86.doi:10.12813/kieae.2015.15.4.085.

[10] Stein, J. S. (2017). PV Performance Modeling Methods and Practices Results from the fourth PV Performance Modeling Collaborative Workshop. Retrieved from: http://ieapvps.org/fileadmin/dam/public/report/technical/T13_Report_PV_P erfor-

mance_Modeling_Methods_and_Practices_FINAL_March_2017.p df.

[11] PV Performance modeling collaborative. (2018). retrieved from: https://pvpmc.sandia.gov/modeling-steps/2-dc-module-iv/moduletemperature/faiman-module-temperature-model/. 